\title{
"O direito de evitar": planejamento familiar nas páginas da revista Veja (década de 1980)
}

\begin{abstract}
Resumo
Durante a década de 1980, o planejamento familiar foi tema de diversas matérias veiculadas pela revista Veja. Neste trabalho, serão analisadas as duas matérias de capa dedicadas ao assunto no referido período. Publicadas em 1981 e 1983, tais matérias problematizaram os perigos que o aumento desenfreado da população brasileira poderia acarretar para a economia do país e exaltaram discursos que reivindicavam a criação de um programa proposto pelo governo. Assim, buscou-se analisar o discurso das reportagens observando especialmente suas questões relativas às famílias e às relações de gênero.
\end{abstract}

Palavras-chave: História; imprensa; família.

\section{Anelise Rodrigues Machado de Araujo}

Doutoranda em História pela Universidade Federal Fluminense - Brasil. anelise.hst@gmail.com

\footnotetext{
Para citar este artigo:

ARAUJO, Anelise Rodrigues Machado de. "O direito de evitar": planejamento familiar nas páginas da revista Veja (década de 1980). Revista PerCursos. Florianópolis, v. 15, n.28, p. 376 - 389. jan./jun. 2014.
}

DOI: $10.5965 / 1984724215282014376$

http://dx.doi.org/10.5965/1984724215282014376 


\title{
"The right to avoid": family planning in the pages of Veja magazine (1980's)
}

\begin{abstract}
During the 1980's, family planning has been the subject of several articles published by Veja magazine. In this paper, we analyze the two cover stories devoted to the subject in that period. Published in 1981 and 1983, such matters problematized the dangers that uncontrolled increase of the Brazilian population could entail to the country's economy and exalted speeches who demanded the creation of a program proposed by the government. Thus, we tried to analyze the speech of their reports noting especially issues relating to families and gender relations.
\end{abstract}

Keywords: History; press; family. 
No tempo presente, um periódico impresso da Editora Abril, é reconhecido como a revista mais lida do Brasil. Lançada apenas dois anos após a instauração da ditadura civilmilitar brasileira, em setembro de 1968, a revista Veja alcançou tal status em menos de uma década de veiculação. Desde então, produziu notícias e acontecimentos sobre as principais pautas nacionais, especialmente as de cunho político.

No início da década de 1980, o planejamento familiar foi um dos temas mais recorrentes em suas páginas. Durante o período compreendido entre 1979 e 1990', o tema esteve presente em 66 das 623 edições analisadas. Destas, destacam-se duas grandes reportagens: uma veiculada no ano de 1981; outra, no ano de 1983. Apesar disso, a maior quantidade de matérias sobre o assunto emerge nas páginas da revista no final da década de 1980. O objetivo deste artigo é refletir brevemente sobre o discurso (re)produzido pela revista nessas duas matérias, a partir de seus elementos textuais.

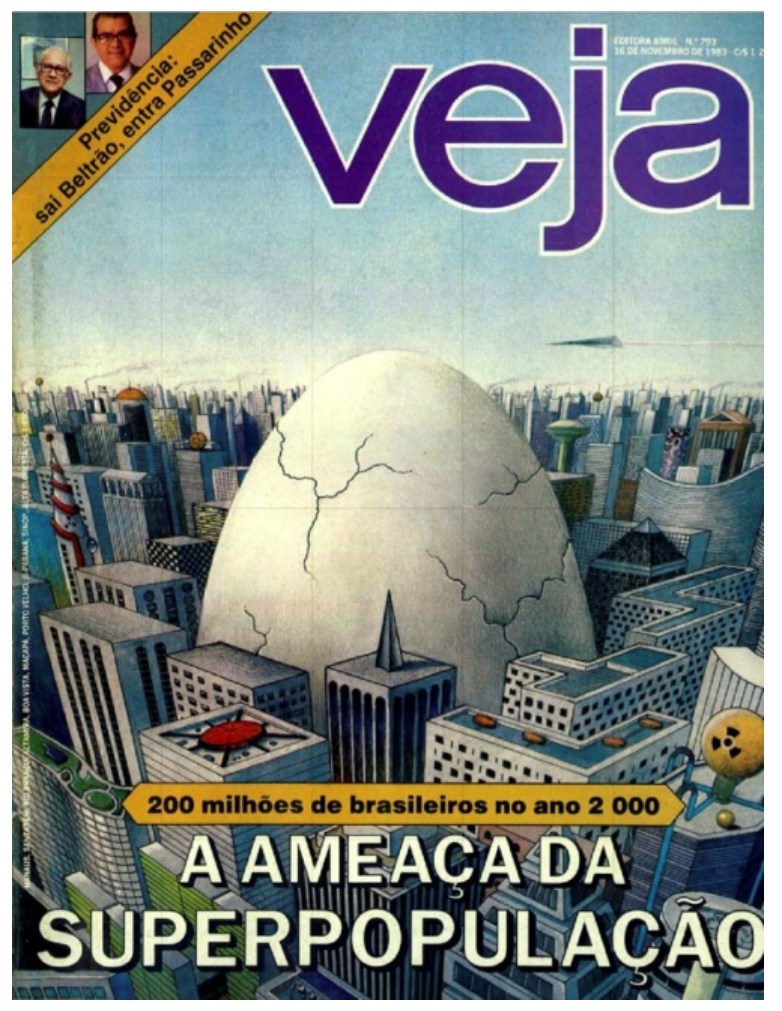

\footnotetext{
${ }^{1}$ Este artigo é uma revisão do subcapítulo 2.1 de minha Dissertação de Mestrado defendida em 2013 junto ao PPGH/UDESC. A pesquisa foi realizada na revista Veja, no período de 1979 a 1990, e contou com financiamento através de bolsa pela Capes.
} 
Na edição de 16 de novembro de 1983, a revista Veja estampou em sua capa a manchete: "A ameaça da superpopulação: 200 milhões de brasileiros no ano 2000" (VEJA, ed. 793, p. 72-80). As semelhanças com a matéria de quatro anos antes, intitulada "O futuro ameaçado: no ano 2000 o Brasil terá 80 milhões de crianças. Será possível pensar em prosperidade sem resolver seus problemas básicos?" (VEJA ed. 559, p. 50-56), não param no título. Ambas as matérias ocuparam uma sequência numerosa de páginas; fizeram uso de dados estatísticos para comprovar os dados alarmantes que apresentavam e citaram entrevistas com pessoas consideradas especialistas nos debates em torno do assunto. Citar suas fontes, aliás, fazia parte da fórmula jornalística da revista.

Após seus três primeiros anos (até 1971) gerando prejuízos à Editora Abril, a revista passou por reformulações em sua linha editorial (ALMEIDA, 2008, p. 53-56). Maria Fernanda Lopes de Almeida explicita que não foi fácil para a equipe de Veja encontrar um estilo de redação que fosse bem aceito pelo público leitor brasileiro. Diante das revistas ilustradas, tão comuns no Brasil até então, houve, por parte do público leitor, um estranhamento com relação à quantidade de texto, que caracterizava a revista lançada em 1968. A Veja só se tornou lucrativa para sua editora a partir de 1974.

No período compreendido entre 1971 e 1974, época em que a melhora nas vendas serviu para pagar os prejuízos dos anos anteriores, a revista foi alvo do trabalho de edição de seus gestores. Afinal, "editar uma revista é organizar os diversos elementos que compõem suas páginas, de maneira a transmitir para o leitor uma mensagem clara sobre tema e conteúdo que formam a matéria" (CORRÊA, 2008, p. 227). Dentre as novidades no formato da revista, estavam as tentativas de conferir maior credibilidade às informações contidas em suas matérias. Para isso, os repórteres de Veja passaram a descrever minuciosamente os acontecimentos e a citar os personagens envolvidos; quando estes eram denunciados por algum ato condenável, deixavam explícito que os envolvidos haviam sido procurados pela reportagem para dar sua versão sobre o caso. O uso de fotografias passou a ser considerado uma prova do conteúdo do texto, exaltando a importância do fotojornalismo. Assim, Veja conseguiu cair no gosto do público leitor brasileiro, mantendo a condição de revista semanal de informação. 
A chamada para uma reportagem sobre "A ameaça da superpopulação" (VEJA, ed. 793), na capa, explicita a importância do assunto para a época. Estabelecida no mercado como uma revista de consumo ${ }^{2}$, as capas de Veja são fundamentais para gerar interesse por seu conteúdo e, assim, ser desejada pelo público leitor e, sobretudo, consumidor. Conforme analisa Tânia Regina de Luca:

O pesquisador dos jornais e das revistas trabalha com o que se tornou notícia, o que por si só já abarca um espectro de questões, pois será preciso dar conta das motivações que levaram à decisão de dar publicidade a alguma coisa. Entretanto, ter sido publicado implica atentar para o destaque conferido ao acontecimento, assim como para o local em que se deu a publicação: é muito diverso o peso que figura na capa de uma revista semanal ou na principal manchete de um grande matutino e o que fica relegado às páginas internas (LUCA, 2006, p. 140).

Logo, o espaço dedicado às investidas em torno do planejamento familiar, considerado um meio de combate à superpopulação do Brasil, torna evidente que o assunto esteve na ordem do dia durante a década de 1980. Assim, a matéria de 1983 afirmou que, "graças sobretudo a países como o Brasil, a população do planeta continua a acusar saltos gigantescos" e, assim, "nessa marcha, o país chegará ao ano 2000 com cerca de 200 milhões de habitantes. Então, sofrerá os efeitos do sensível agravamento da pobreza e da queda da qualidade de vida" (VEJA, ed. 793, p. 74).

Entre 1970 e 1983, a população brasileira cresceu, segundo a reportagem, o equivalente à soma das populações de Argentina, Uruguai e Paraguai, ou seja, passou a contar com 34 milhões de habitantes a mais em seu território (VEJA., ed. 793, p. 75). Contudo, a preocupação exaltada pela revista estava no futuro, na ameaça que esse inchaço populacional poderia significar para o desenvolvimento do País e da vida social cotidiana. A solução seria, então, aderir ao planejamento familiar, assunto que já vinha sendo discutido pelo poder público e pelos setores médicos.

\footnotetext{
${ }^{2}$ Revista de consumo, na concepção de Thomaz Souto Corrêa (2008), é o tipo de revista vendida por assinatura e/ou em bancas e demais estabelecimentos de comércio. O autor diferencia as revistas de consumo das revistas especializadas. Estas, geralmente gratuitas, tratam de temas relativos a grupos profissionais específicos. No Brasil, as revistas de consumo proliferaram principalmente a partir da segunda metade do século XX.
} 
No mundo ocidental, nem sempre as famílias foram compreendidas como um segmento no qual o Estado poderia interferir. Michel Foucault aponta uma ruptura quando, entre os séculos XVI e XVIII, houve uma redefinição nos modelos políticos (1986, p. 277). Antes disso, era comum os príncipes receberem conselhos sobre como reforçar e proteger seu principado, conforme exemplifica a obra O Príncipe, de Nicolau Maquiavel. A obra deste autor, datada do século XVI, é tomada por Foucault (1986, p. 280)como um tratado que versava sobre a habilidade de conservar seu território e sua população. Ao mesmo passo, a literatura anti-Maquiavel, escrita após O Príncipe, é analisada pelo autor como um indício das mudanças que colocaram em cena a arte de governar De acordo com Foucault (1986) a partir dessa ruptura, verificada na pluralidade das formas de governo, estabeleceu-se uma continuidade na arte de governar o indivíduo, a família e o Estado, tanto na direção ascendente quanto descendente. Partindo de constatações que ponderam que um Estado bem governado exemplifica para as famílias como exercer a arte de governar e que esse exemplo se estende aos indivíduos, ou que para bem governar um Estado o indivíduo deve primeiro governar-se e governar sua família, o autor explicita que o elemento central desse sistema é o governo da família. Logo, "a pedagogia do príncipe assegura a continuidade ascendente da forma de governo; a polícia, a continuidade descendente" (FOUCAULT, 1986, p. 281). Ocorreu, deste modo, a instrumentalização da família nos Estados modernos:

Em outras palavras, até o advento da problemática da população, a arte de governar só podia ser pensada a partir do modelo da família, a partir da economia entendida como gestão da família. [...] Este deslocamento da família no nível de modelo para o nível de instrumentalização me parece absolutamente fundamental, e é a partir da metade do século XVIII que a família aparece nesta dimensão instrumental em relação à população, como demonstram as campanhas contra a mortalidade, as campanhas relativas ao casamento, as campanhas de vacinação, etc. (FOUCAULT, 1986, p. 289).

A família, compreendida como um elo entre Estado e indivíduo, passou a ser um dos principais instrumentos de gestão da população. Concomitantemente, tornou-se um objeto constante de governo, sendo, portanto, normalizada para adequar seus indivíduos 
à disciplina. Afinal, "gerir a população significa geri-la em profundidade, minuciosamente, no detalhe" (FOUCAULT, p. 291). Assim também o entende Jacques Donzelot (1980, p. 51), quando afirma que o Estado se apoia na família para assegurar a ordem pública

A configuração de família, prescrita pela norma burguesa, atribui lugares tradicionais de gênero e geração bastante delineados. Seguindo esse modelo, a relação conjugal, heteroafetiva, fundamenta-se no casamento e no amor romântico entre os cônjuges. O psicanalista Jurandir Freire Costa (2004, p. 228)afirma que tanto o casamento quanto o amor romântico atendem aos ideais da medicina higienista, posto que pregam a monogamia e, por conseguinte, evitariam que os homens casados fizessem uso dos serviços do mercado sexual Além disso, a família sustentada pelo amor romântico reforçaria os vínculos com sua prole, protegendo as crianças. E, por fim, o amor ainda regularia os lugares tradicionais de homens, mulheres e crianças (COSTA, 2004, p. 234).

No interior desse ideal de família, um dos objetivos da medicina higienista era que cada membro do núcleo possuísse suas funções. As crianças, para as quais se voltariam as preocupações dos demais membros da família, deveriam ser preparadas para o futuro. Segundo Costa, "a nova criança reclamava um casal que, ao invés de se comportar como proprietário, aceitasse, prioritariamente, ser tutor" (COSTA, 2004, p. 170). Com isso, homens pais deveriam se responsabilizar pelo sustento do quadro familiar, sendo os provedores da casa. Às mulheres caberia o papel de responsáveis pela educação infantil e de principais responsáveis pelo desenvolvimento saudável das crianças, sendo ele físico, moral e intelectual. A maternidade tornou-se o lugar tradicional das mulheres.

Logo, a família nuclear, de tamanho reduzido e pautada na afetividade, estaria em melhores condições para cuidar de sua prole. No Brasil, as matérias da revista Veja explicitam essa nova relação com o tamanho das famílias. A reportagem de 1983 sobre a ameaça da superpopulação se inicia com a história do casal Raimundo Carnaúba e Maria Madalena de Sousa, casados há 48 anos, e com 32 filhos. Para Raimundo, ter gerado mais de três dezenas de crianças era motivo de orgulho. Migrante do interior do Ceará para Brasília em 1959, o casal protestava contra a interferência do poder público no tamanho das famílias. 
E não esteve (o casal) sozinho. Parte da falta de consenso sobre o planejamento familiar ocorreu porque se questionava até onde o Estado poderia interferir em decisões, até então consideradas íntimas ou “de Deus”. Em 1987, a revista Veja veiculou, em uma de suas páginas, uma peça publicitária de diversas instituições ligadas ao planejamento familiar, distinguindo-o de controle da natalidade. Exaltando os benefícios do planejamento, a publicidade defendia: “o controle da natalidade é a intervenção direta do Estado no foro íntimo da família, impondo o limite de seus filhos. Um atentado a um direito universal" (Revista VEJA, Ed. 983, p. 52), enquanto o planejamento era descrito como democrático, avançado, baseado no saber científico e com o objetivo de melhorar a saúde materno-infantil.

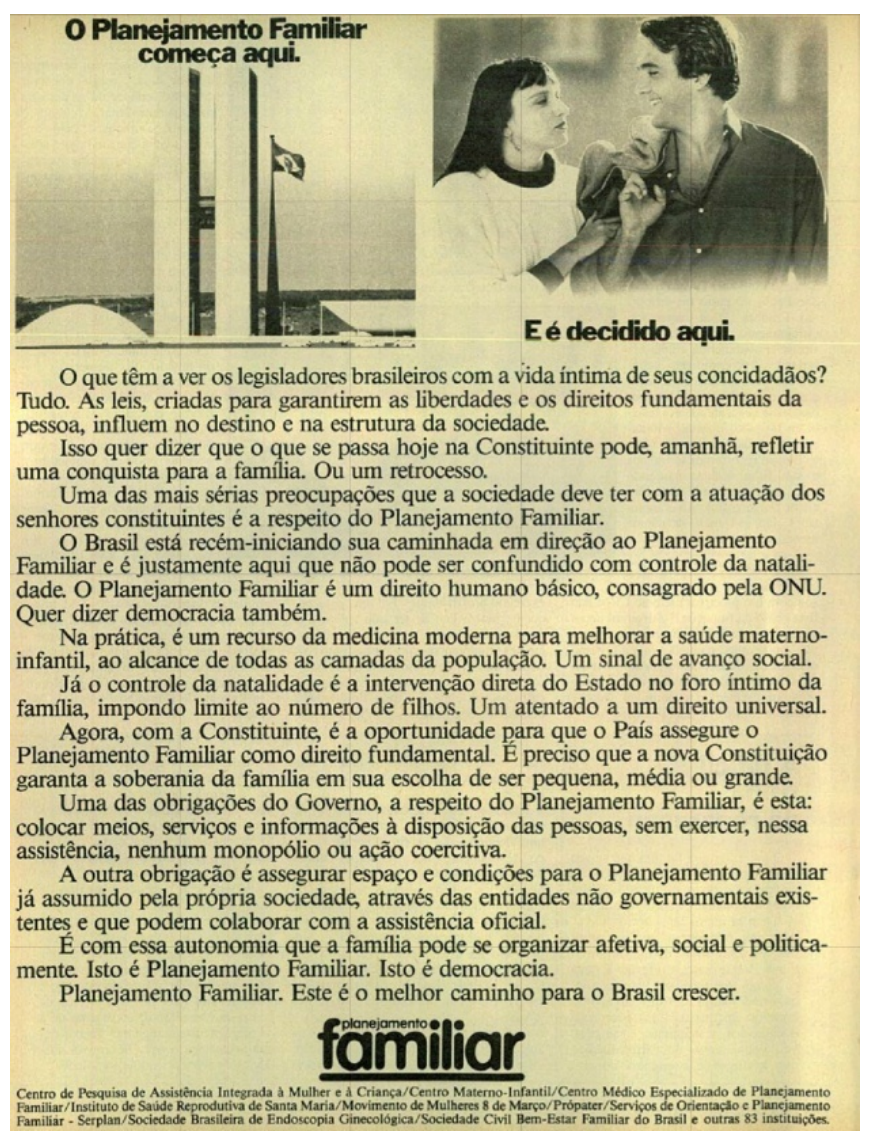

A revista mostrou situações casos como as do casal Raimundo e Maria Madalena tenderiam, cada vez mais, a ser exceção. Segundo a reportagem, "ele [Raimundo Carnaúba] pertence a um tempo em que muitos filhos significavam mais braços para o trabalho e vem de um mundo governado pela crença de que os pais não podiam determinar o tamanho da sua família" (VEJA, ed. 793, p. 73). Contudo, esse cenário 
deveria modificar-se, principalmente porque, através dos métodos anticoncepcionais, seria possível limitar o número de filhos. Além disso, o Estado brasileiro havia assumido a questão como um problema social que cerceava o crescimento do País e a comparação com os países mais desenvolvidos do mundo indicava uma séria diferença. De acordo com o texto e com tabelas contidas na matéria, as taxas de fecundidade, ou seja o número de filhos e filhas por mulher, nos países mais ricos, eram bem menores do que no Brasil.

Em apoio à informação, Veja apresentava as contribuições médicas para que a taxa de fecundidade passasse a ser controlada e, assim, reduzida. Chamados pela revista de "os métodos para não ter filhos", foram apresentados os seguintes: diafragma, vasectomia, muco vaginal, pílula, DIU, amarração das trompas, tabelinha e espermaticidas (VEJA, ed. 793, p. 76). Ao mesmo tempo, segundo a reportagem, muitos homens resistiam ao uso desses métodos porque alegavam que só os que mantinham relações sexuais fora do casamento é que precisavam desse aparato. Por outro lado, trouxe histórias de mulheres, como a de Maria Ione, que teve apenas dois filhos. Casada com um empregado da Construtora Andrade Gutierrez, empresa que implementara entre seus funcionários um programa de planejamento familiar, Maria lone deixava explícito que a responsabilidade e o aprendizado para não engravidar haviam partido dela e que estava satisfeita com sua quantidade de filhos (VEJA, ed. 793, p. 74).

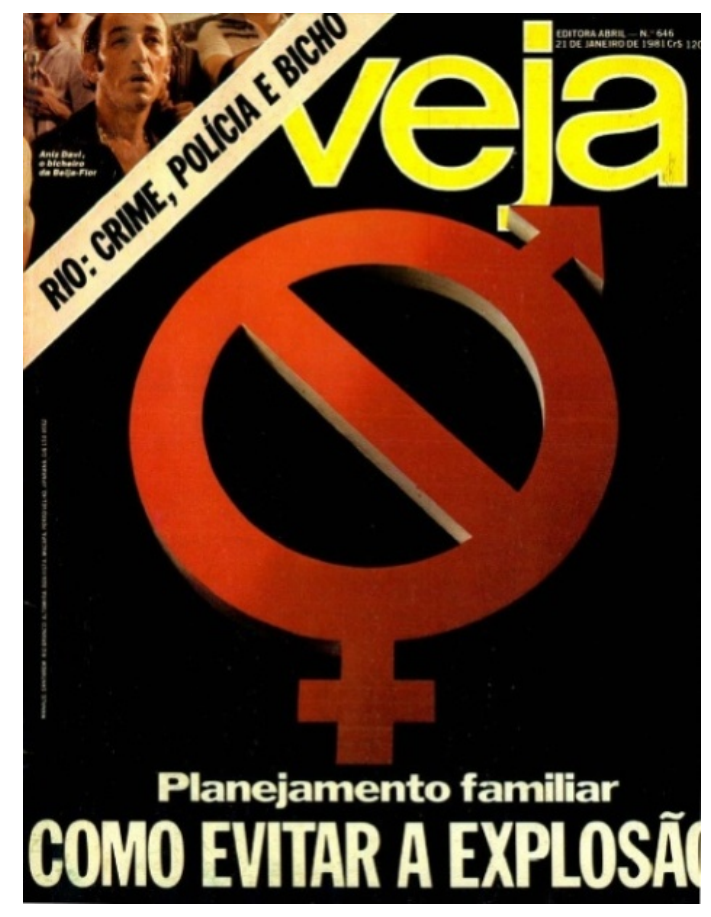


Em 1981, a revista veiculou outra matéria com tom bastante semelhante, inclusive no que tange à responsabilização da mulher pelo tamanho da família. Orientar as "mães", segundo a reportagem, sobre "o direito de evitar" seria o meio de controlar o crescimento populacional brasileiro e reduzir o número de abortos ocorridos no País. Entretanto, o texto apresentava o problema como fundamentalmente pautado na questão de classe, pois acreditava que, "como ocorreu há muito tempo com mulheres da camada média e das camadas ricas, as mulheres pobres de hoje recorrem em número crescente a fórmulas que limitem o tamanho de suas famílias" (VEJA, ed. 646, p. 59). Frente a isso, criticou-se a demora do governo brasileiro em guiar os rumos do planejamento familiar, o que até então vinha sendo feito por entidades privadas, que tinham maior dificuldade em atingir as camadas populares.

A pílula anticoncepcional começou a ser comercializada no Brasil em 1962 e, a partir de então, o número de mulheres que aderiam ao medicamento não parava de crescer. "Em 1970, 6,8 milhões de cartelas de pílulas anticoncepcionais foram vendidas e, em 1980, este número subiu para 40,9 milhões" (PEDRO, 2003, p. 243). Contudo, a revista Veja expôs um empecilho ao uso do método. Para a Igreja Católica, evitar uma gravidez através da pílula seria um método antinatural e com consequências ainda incalculáveis sobre seu uso, argumento veementemente rechaçado pela revista:

Mas, da mesma forma que o governo procura adoçar com preocupações médicas providências na verdade concebidas para reduzir a expansão populacional, é provável que o secretário geral da CNBB esteja colorindo com argumentos científicos restrições de fundo exclusivamente religioso (VEJA, ed. 646, p. 56).

Na reportagem de 1983, uma mudança pode ser verificada nesse discurso religioso, quando se afirmou haver vozes discordantes no interior da Igreja . Segundo a matéria, "apesar da dura oposição do papa João Paulo II a qualquer técnica contraceptiva, religiosos de diferentes partes do mundo vão admitindo que é preciso abrir o leque dos métodos que permitem planejar a família" (VEJA, ed. 793, p. 76). Afinal, acreditava-se que a Igreja vinha perdendo fiéis devido a seu posicionamento contrário ao 
planejamento familiar, conforme afirmou o padre Hubert Lepargneur à reportagem veiculada na revista Veja. A doutrina oficial da Igreja católica, que condenava o uso de métodos contraceptivos por considerá-los "antinaturais", foi descrita como algo que estava na contramão da resolução de uma proeminente questão social. Na perspectiva de Rubens Costa, economista entrevistado pela revista Veja, "antinatural” seria, no caso, exigir que as pessoas controlassem seus ímpetos sexuais de modo a praticar a abstinência pregada pela Igreja como alternativa para o controle da natalidade (VEJA ed. 793, p. 75).

Ao mesmo tempo em que a revista veiculava um discurso explicitamente prócontrole da natalidade, fundamentava suas premissas na (re)construção de um "inimigo" do desenvolvimento nacional. Segundo a matéria "O direito de evitar", a limitação da natalidade era "um dos fantasmas favoritos da esquerda brasileira [...]" (VEJA ed. 646, p. 56). Os grupos comunistas eram retratados pela reportagem como resistentes ao planejamento familiar por acreditarem que a distribuição de renda melhoraria apenas com o socialismo e que o País precisava ocupar seus vazios demográficos. Contudo, Joana Maria Pedro afirma:

O investimento no controle da natalidade no Brasil, e em outros países da América Latina, teve relação direta com a Revolução Cubana de 1959. A partir daí, a política norte-americana passou a considerar a América Latina como um "continente explosivo", um campo fértil para a agitação comunista (PEDRO, 2003, p. 242).

Portanto, os interesses da revista Veja em defender o controle populacional e, ao mesmo tempo, condenar a esquerda política mesclam-se numa representação ambígua entre desenvolvimento econômico e planejamento familiar. Desde a sua primeira edição, em setembro de 1968, a revista fez sucessivas críticas aos países comunistas, principalmente à Rússia, considerada uma "vilã" imperialista, e afirmou, naquela mesma, edição que a União das Repúblicas Socialistas Soviéticas (URSS) ainda deveria se rebelar contra Moscou (KLANOVICZ, 2010, p. 41). Assim, nunca escondeu que o viés da publicação 
era contrário à esquerda e que não compactuava com a inserção de grupos comunistas no Brasil.

Segundo a historiadora Lenita Raad (2005), principalmente durante a década de 1960, devido ao início das vendas das pílulas anticoncepcionais, houve na América Latina um embate entre grupos antinatalistas e anticontrolistas. Entre os anticontrolistas estiveram membros da Igreja Católica, de movimentos de cunho nacionalista e do movimento feminista. Partes desses grupos não apoiavam o intervencionismo do Estado no planejamento familiar e, particularmente para o movimento feminista, nos corpos das mulheres. Já os antinatalistas se apoiavam em estatísticas, que iam desde o perigo da superpopulação ao número de abortos realizados, para exaltar a necessidade de programas que controlassem as taxas de natalidade dos países não "desenvolvidos". Foram esses grupos que apoiaram a criação de programas como o "Aliança Para o Progresso", assinado pelo então presidente dos Estados Unidos, John Fitzgerald Kennedy, em 1961, como resposta à Revolução Cubana, e com vistas a acelerar o desenvolvimento da América Latina - ao mesmo passo em que tentaria frear o avanço comunista em tais territórios.

Os debates sobre planejamento familiar, por isso, não estiveram isolados dos acontecimentos mundiais. A matéria "A ameaça da superpopulação" afirmava que se acreditava, "ingenuamente", que o planejamento familiar era um complô dos países ricos (VEJA, ed. 793, p. 74). Ao atribuir ao Partido Comunista Brasileiro a frase "o melhor anticoncepcional é o desenvolvimento econômico", Veja constrói sua concepção sobre o quanto planejamento e crescimento são aliados valiosos. De certa maneira, as influências das experiências de controle populacional de outros países colocaram em pauta a relação entre o Brasil e o cenário internacional. 


\section{Referências}

ALMEIDA, Maria Fernanda Lopes. VEJA sob censura (1968-1976). São Paulo: Jaboticaba, 2008.

ARAUJO, Anelise Rodrigues Machado de. A revista Veja nos tempos da redemocratização: um olhar sobre a infância (1979-1990). 2013. 115 p. Dissertação (Mestrado em História) Universidade do Estado de Santa Catarina, Florianópolis, 2013.

CORRÊA, Thomaz Souto. A era das revistas de consumo. In: LUCA, Tania Regina de, MARTINS, Ana Luiza (Org.). História da imprensa no Brasil. São Paulo: Contexto, 2008. p. 207- 232.

COSTA, Jurandir Freire. Ordem médica e norma familiar. Rio de Janeiro: Edições Graal, 2004 .

DONZELOT, Jacques. A polícia das famílias. Rio de Janeiro: Graal, 1980.

FOUCAULT, Michel. A ordem do discurso. São Paulo: Edições Loyola, 2008.

FOUCAULT, Michel. Microfísica do poder. Rio de Janeiro: Graal, 1986.

KLANOVICZ, Luciana Rosar Fornazari. No olho do furacão: revista Veja, censura e ditadura militar (1968-1985). Revista Literatura em Debate, v. 4, n. 6, p. 34-50, jan./jul., 2010.

Disponível em: < http://www.fw.uri.br/publicacoes/literaturaemdebate/artigos/3L6.pdf >.

KOSELLECK, Reinhart. Futuro passado: contribuição à semântica dos tempos históricos. Rio de Janeiro: Editora PUC-Rio, Contraponto, 2006.

LUCA, Tânia Regina. História dos, nos e por meio dos periódicos. In: PINSKY, Carla (Org.). Fontes históricas. São Paulo: Editora Contexto, 2006. p. $111-153$.

PEDRO, Joana Maria. A experiência com contraceptivos no Brasil: uma questão de geração. In: Revista Brasileira de História. v.23, n.45, p. 239-260, 2003.

PEDRO, Joana Maria. As representações do corpo feminino nas práticas contraceptivas, abortivas e no infanticídio. In: MATOS, Maria Izilda S. de ; SOIHET. Rachel (Org.). O corpo feminino em debate. São Paulo: Editora UNESP, 2003, p. 157-176.

RAAD, Lenita Jacira Faria. Denunciando os males do comunismo: o anticomunismo na revista Seleções do Reader's Digest (1950-1960). 2005. 135 p. Dissertação (Mestrado em História) - Universidade Federal de Santa Catarina, Florianópolis, 2005. 
"O direito de evitar": planejamento familiar nas páginas da revista Veja (década de 1980)

Anelise Rodrigues Machado de Araujo

Recebido em: 20/09/2013

Aprovado em: 15/05/2014

Universidade do Estado de Santa Catarina - UDESC

Centro de Ciências Humanas e da Educação - FAED

Revista PerCursos

Volume 15 - Número 28 - Ano 2014 revistapercursos@gmail.com 